OPEN ACCESS

Edited by:

William Small, Jr.,

Loyola University Chicago,

United States

Reviewed by:

Valentina Lancellotta,

Catholic University of the Sacred

Heart, Italy

San-Gang Wu,

First Affiliated Hospital of Xiamen

University, China

*Correspondence:

Ming Li

liming3259@126.com

these authors have contributed equally to this work

Specialty section:

This article was submitted to

Radiation Oncology,

a section of the journal

Frontiers in Oncology

Received: 29 July 2020 Accepted: 05 November 2020 Published: 11 December 2020

Citation:

Li M, Yue J, Wan X, Hua B, Yang Q,

Yang $P$, Zhang Z, Pei Q, Han W, Xu Y and Xia $X$ (2020) Risk-Adapted Postmastectomy Radiotherapy Decision Based on Prognostic Nomogram for PT1-2N1MO Breast Cancer: A Multicenter Study.

Front. Oncol. 10:588859. doi: 10.3389/fonc.2020.588859

\section{Risk-Adapted Postmastectomy Radiotherapy Decision Based on Prognostic Nomogram for pT1-2N1M0 Breast Cancer: A Multicenter Study}

Ming $\mathrm{Li}^{1 * t}$, Jinbo Yue ${ }^{2+}$, Xiangbo $\mathrm{Wan}^{3 \dagger}$, Bin Hua ${ }^{4}$, Qiuan Yang ${ }^{5}$, Pei Yang ${ }^{6}$, Zijian Zhang ${ }^{7}$, Qian $\mathrm{Pe}^{8}{ }^{8}$, Weidong Han ${ }^{9}$, Yaping $\mathrm{Xu}^{10}$ and Xuefeng Xia ${ }^{10}$

${ }^{1}$ Department of Radiation Oncology, Beijing Hospital/National Center of Gerontology, Beijing, China, ${ }^{2}$ Department of Radiation Oncology, Shandong Cancer Hospital Affiliated to Shandong University/Shandong Academy of Medical Sciences, Jinan, China, ${ }^{3}$ Department of Radiation Oncology, The Sixth Affiliated Hospital - Sun Yat-sen University, Guangzhou, China, ${ }^{4}$ Department of Breast Cancer Surgery, Beijing Hospital/National Center of Gerontology, Beijing, China, ${ }^{5}$ Department of Radiation Oncology, Qilu Hospital of Shandong University, Jinan, China, ${ }^{6}$ Department of Radiation Oncology, Hunan Cancer Hospital/The Affiliated Cancer Hospital of Xiangya School of Medicine - Central South University, Changsha, China, ${ }^{7}$ Department of Radiation Oncology, Xiangya Hospital - Central South University, Changsha, China, ${ }^{8}$ Department of General Surgery, Xiangya Hospital - Central South University, Changsha, China, ${ }^{9}$ Department of Medical Oncology, Sir Run Run Shaw Hospital, College of Medicine, Zhejiang University, Hangzhou, China, ${ }^{10}$ Geneplus-Beijing Institute, Beijing, China

Purpose: The aim of this study was to develop a widely accepted prognostic nomogram and establish a risk-adapted PMRT strategy based on locoregional recurrence for pT12N1M0 breast cancer.

Methods and Materials: A total of 3,033 patients with pT1-2N1M0 breast cancer treated at 6 participating institutions between 2000 and 2016 were retrospectively reviewed. A nomogram was developed to predicted locoregional recurrence-free survival (LRFS). A propensity score-matched (PSM) analyses was performed in riskadapted model.

Results: With the median follow-up of 65.0 months, the 5-year overall survival (OS), disease free survival (DFS) and LRFS were 93.0, 84.8, and 93.6\%, respectively. There was no significant difference between patients who received PMRT or not for the entire group. A nomogram was developed and validated to estimate the probability of 5-year LRFS based on five independent factors including age, primary tumor site, positive lymph nodes number, pathological T stage, and molecular subtype that were selected by a multivariate analysis of patients who did not receive PMRT in the primary cohort. According to the total nomogram risk scores, the entire patients were classified into low- $(40.0 \%)$, moderate(42.4\%), and high-risk group (17.6\%). The 5-year outcomes were significantly different among these three groups $(\mathrm{P}<0.001)$. In low-risk group, patients who received PMRT or not both achieved a favorable OS, DFS, and LRFS. In moderate-risk group, no differences in OS, DFS, and LRFS were observed between PMRT and no PMRT patients. In high-risk group, compared with no PMRT, PMRT resulted in significantly different OS (86.8 vs 
83.9\%, $P=0.050)$, DFS (77.2 vs $70.9 \%, P=0.049)$, and LRFS (90.8 vs. $81.6 \%, P=$ 0.003). After PSM adjustment, there were no significant differences in OS, DFS, and LRFS in low-risk and moderate-risk groups. However, in the high-risk group, PMRT still resulted in significantly better OS, DFS and improved LRFS.

Conclusions: The proposed nomogram provides an individualized risk estimate of LRFS in patients with pT1-2N1M0 breast cancer. Risk-adapted PMRT for high-risk patients is a viable effective strategy.

Keywords: breast neoplasms, mastectomy, radiation therapy, nomogram, risk-adapted therapy, molecular subtype, prognosis, recurrence

\section{INTRODUCTION}

In the past 3 decades, breast cancer has been recognized as a heterogeneous clinicopathological course. Primary tumor size (T stage) and number of axillary lymph nodes metastasis $(\mathrm{N}$ stage) are the most important factors affecting the locoregional recurrence and survival rate (1). Postmastectomy radiotherapy (PMRT) has been demonstrated to bring significant clinical benefits for high-risk patients in locoregional recurrence after mastectomy and systemic treatments (2-5). Relevant guidelines or consensus recommend that PMRT should be delivered for patients with tumor size more than $5 \mathrm{~cm}$ or with 4 or more axillary positive lymph nodes (stage T3-4 or N2-3), - infiltration of the skin, and/or the pectoral muscle, inflammatory carcinoma and positive margins. Patients with $1-3$ positive axillary lymph nodes of early stage breast cancer (stage T1-2N1) have locoregional recurrence rate (LRR) of approximately 10-20\% after mastectomy. Multiple retrospective analyses or subgroup analyses have highlighted the clinical benefit of PMRT for N1 patients (6-13). The results of Early Breast Cancer Trialists' Collaborative Group (EBCTCG) meta-analysis showed that PMRT after mastectomy and axillary node dissection reduced both LRR and breast cancer mortality in patients with N1 stage breast cancer even when systemic therapy was administered (14). But due to the lack of randomized controlled and large-sample studies, the optimal therapy for $\mathrm{N} 1$ patients is still equivocal. It is not clear whether these patients need radiotherapy. Whether patients with T1-2N1 breast cancer should be treated with PMRT is also controversial, and there were no direct evidences to support the application of PMRT in T1-2N1 patients.

The 2018 ATTM meeting also presented that PMRT might be safely omitted in some early stage with good prognostic features breast cancer patients who received PST, and attempts were made to identify such patients. As recommendations were not uniform, doubts persist about which candidates can safely omit PMRT. The ATTM suggested that biomarker assessments might improve understanding of breast cancer biology and behavior (15).

In this study, we develop a widely accepted prognostic nomogram for the estimation of LRR for pT1-2N1M0 breast cancer. Then we stratified the patients into different risk categories based on the total nomogram risk scores, compare the efficacy of PMRT in different risk stratification, and finally optimize a risk-adapted therapeutic strategy.

\section{METHODS AND MATERIALS}

\section{Patient Eligibility}

A total of 3,033 female patients with previously untreated infiltrating breast cancer with T1,2 disease and 1 to 3 positive lymph nodes who were treated with mastectomy followed by adjuvant systemic therapy at 6 participating institutions between 2000 and 2016 were retrospectively reviewed. To develop a nomogram prognostic model, all patients were divided into 2 cohorts. The primary cohort comprised 2031 patients from 4 institutions, and the validation cohort consisted of an independent series of 1,002 patients from the rest 2 institutions. All patients had complete clinical information and underwent standard staging procedures. Other eligibility requirements included typical histological and immunophenotypic features of breast cancer (World Health Organization (WHO) classification), pT1-2N1M0 disease (American Joint Committee on Cancer (AJCC) staging system), and complete follow-up information. Patients who had bilateral breast cancer or other malignances before or meanwhile or less than 1 year follow up time were excluded. This project was approved by the ethics committee at the Beijing Hospital/National Center of Gerontology and conducted in accordance with the Helsinki declaration of the World Medical Association (the $5^{\text {th }}$ revision in October 2000).

One of the variables adequately evaluated was the phenotype of immunohistochemical (IHC) receptor [including estrogen receptor (ER), progesterone receptor (PR), Human epidermal growth factor receptor 2 (Her2), and Antigen identified by monoclonal antibody $\mathrm{Ki}-67$ (Ki-67)], which allowed us to categorize patients into 4 molecular subtypes (St. Gallen consensus 2013) as Luminal A (ER+ or PR+, HER2-), Luminal $\mathrm{B}(\mathrm{ER}+$ or PR+, HER2+), Her2 enriched (ER-, PR-, HER2+), and Triple negative (ER-, PR-, HER2-).

\section{Treatment}

There were 851 (28.1\%) patients received PMRT, and 2182 (71.9\%) without PMRT. Target of PMRT included chest wall with infraclavicular (axillary level III) and supraclavicular fields at a median dose of 50Gy (range, 46-50.4Gy; dose per fraction, 1.8-2Gy). Internal mammary nodes were irradiated when the tumor located in inner and central region.

All patients received breast cancer mastectomy with negative surgical margin. There are $95.8 \%$ patients with sufficient lymph 
node dissection that was defined as at least 10 lymph nodes removed. The median axillary lymph node numbers of dissection were 20. All patients received CT, among which 553 (18.2\%) received cyclophosphamide-doxorubicin-fluorouracil (CAF) or adriamycin-contained regimens, whereas 2,480 (81.8\%) received taxanes-based regimens. The number of CT cycles ranged from 6 to 8 . There were 2,150 patients received at least 5 years of endocrine treatment, which accounted for $92.0 \%$ of all hormone receptor-positive patients. Among them, 973 (45.3\%) patients were treated with aromatase inhibitors (AI). There were 617 (20.3\%) patients had known HER2 positive status and among which $171(27.7 \%)$ were treated with trastuzumab. The median lasting time of all targeted treatments was 12 months.

\section{Statistical Analyses}

The primary endpoint of this study was locoregional recurrencefree survival (LRFS) as calculated from the start of initial surgical treatment until the time of locoregional recurrence, or until the last follow-up. LRR was defined as tumor recurrence in the ipsilateral chest wall, and supraclavicular, axillary or internal mammary lymph nodes. Secondary endpoints were disease-free survival (DFS) and overall survival (OS).

Survival curves were estimated with the Kaplan-Meier method and compared with a log-rank test stratified according to the prognostic factors. Cox proportional hazards regression model was performed to identify independent risk factors for LRFS in the primary cohort. The nomogram was formulated based on the Cox model parameter estimates. There were several steps to validate the efficacy of the nomogram. First, an internal validation was undertaken with a concordance index (C-index) being estimated by analyzing the area under the curve (AUC) of the receiver operating characteristic (ROC) curve. Next, a calibration plot was constructed by comparing the decile of predicted probabilities and actual probabilities using 1,000 bootstrap resamples. Finally, in external validation, the nomogram was used to assess each patient in the validation cohort, and the regression analysis was then used to derive the $\mathrm{C}$-index and the calibration curve. Propensity score-matched (PSM) analysis was conducted to mirror randomized study design and generate comparable study arms; 1:1 patient matching without replacement was used to pair each patient receiving PMRT with another without PMRT whose propensity score was within the designated caliper size (in low-risk group, the ratio is $1: 2$ ). After PSM, baseline covariates and survival rates were compared between treatment groups. OS, DFS, LRFS were assessed with the Kaplan-Meier method, and compared using the log-rank test.

Cox proportional hazards regression was performed with IBM SPSS Statistics, version 25.0. Nomogram construction and validation were performed with Iasonos' guide. Nomogram and bootstrap resampling were performed using the Hmisc, rms, survivalROC package in $\mathrm{R}$, version 3.5 .3 (http://www.r-project. org/). PSM was performed with Stata 15. Other analyses were performed with IBM SPSS Statistics 25.0. A 2-sided P values of less than 0.05 were considered significant.

\section{RESULTS}

\section{Patient Characteristics}

Of all patients, the median age was 50.00 years (range, 21-84). Molecular subtype was presented as Luminal A (64.7\%), Luminal B (12.4\%), Her2 enriched (7.9\%), and Triple negative (14.9\%) types in all patients. The patients' characteristics are presented in Table 1. Similar clinical characteristics were observed in the primary and the validation cohorts.

\section{Construction and Internal Validation of the Nomogram}

We identified clinical features that have previously been demonstrated to be associated with survival, and used univariate analysis to explore the prognostic features of patients who did not receive PMRT in primary cohort. The prognostic factors that predicted poor LRFS included age $\leq 45$ years, premenopausal status, inner and central primary disease site, T2 stage, 2-3 positive lymph nodes, positive lymph nodes percentage $>10 \%$, ER (-), PR (-), Ki-67 $\geq 30 \%$, and Her2 enriched or Triple negative molecular subtype (Table 2 ).

Multivariate analysis demonstrated that age ( $\leq 45$ years vs. $>45$ years), primary tumor site (lateral region vs. inner and central region), molecular subtype (Luminal A vs. Luminal B vs. Her2 enriched vs. Triple negative), pathological T stage (T1 vs. T2) and positive lymph nodes number (1 vs. 2 vs. 3 ) were independent factors for LRFS (Table 3).

A nomogram to predict 5-year LRFS was developed using the prognostic factors from the multivariate analysis (Figure 1). The predictive accuracy for 5-year LRFS was measured by the C-index was 0.735 in the internal validation (Figure 2A). The calibration plot for the probability of 5-year LRFS showed a good correlation between the actual observed outcome and the prediction by the nomogram (Figure 2B).

\section{External Validation of Nomogram for Locoregional Recurrence-Free Survival}

The nomogram was validated to assess each patient who did not receive PMRT in the validation cohort. The $\mathrm{C}$-index of the nomogram for the prediction of the 5-year LRFS was 0.703 in the external validation step (Figure 2C), which demonstrated that it is a model with a good level of discriminative ability. The calibration curve revealed that the nomogram was well calibrated; the 5-year LRFS showed an optimal agreement between the actual observation and the nomogram prediction (Figure 2D).

\section{Locoregional Recurrence Risk Stratification and Survival}

At a median follow up time of 65.00 months (95\% CI: 62.9667.04 months), the 5-year OS, DFS and LRFS were 93.0, 84.8, and 93.6\%, respectively (Figure 3A). There were 215 patients had locoregional recurrence events, including 107 (49.8\%) in ipsilateral chest wall, $42(19.5 \%)$ in axilla lymph nodes, 120 
TABLE 1 | Clinical characteristics of patients with pT1N1M0 breast cancer.

\begin{tabular}{|c|c|c|c|c|c|c|c|}
\hline Characteristic & $\begin{array}{c}\text { All patients } \\
\text { No. (\%) }\end{array}$ & $\begin{array}{c}\text { Primary cohort } \\
\text { No. (\%) }\end{array}$ & $\begin{array}{c}\text { Validation cohort } \\
\text { No. (\%) }\end{array}$ & $P$ value & $\begin{array}{c}\text { PMRT cohort } \\
\text { No. }(\%)\end{array}$ & $\begin{array}{c}\text { No PMRT cohort } \\
\text { No. }(\%)\end{array}$ & $P$ value \\
\hline Total & 3,033 (100) & 2,031 (67.0) & 1,002 (33.0) & & $851(28.1)$ & 2,182 (71.9) & \\
\hline Lateral & & & & 0.601 & & & 0.793 \\
\hline left & $1,537(50.7)$ & $1,036(51.0)$ & $501(50.0)$ & & $428(50.3)$ & 1,109 (50.8) & \\
\hline right & 1,496 (49.3) & 995 (49.0) & $501(50.0)$ & & $423(49.7)$ & 1,073 (49.2) & \\
\hline Age (y) & & & & 0.339 & & & $<0.001$ \\
\hline$\leq 45$ & $982(32.4)$ & $646(31.8)$ & 336 (33.5) & & $351(41.2)$ & $631(28.9)$ & \\
\hline$>45$ & $2,051(67.6)$ & 1,385 (68.2) & $666(66.5)$ & & $500(58.8)$ & $1,551(71.1)$ & \\
\hline Menstrual status & & & & 0.325 & & & $<0.001$ \\
\hline premenopausal & 1,687 (55.6) & 1,117 (55.0) & $570(56.9)$ & & $533(62.6)$ & 1,154 (52.9) & \\
\hline postmenopausal & $1,346(44.4)$ & $914(45.0)$ & $432(43.1)$ & & $318(37.4)$ & $1,028(47.1)$ & \\
\hline Coronary disease & & & & 0.087 & & & 0.530 \\
\hline No & 2,937 (98.0) & 1,997 (98.3) & $976(97.4)$ & & $832(97.8)$ & 2,141 (98.1) & \\
\hline Yes & $60(2.0)$ & $34(1.7)$ & $26(2.6)$ & & $19(2.2)$ & $41(1.9)$ & \\
\hline Primary tumor site & & & & 0.304 & & & 0.025 \\
\hline lateral & $2,248(74.1)$ & $1,517(74.7)$ & $731(73.0)$ & & $655(77.0)$ & 1,593 (73.0) & \\
\hline Inner+central & 785 (25.9) & 514 (25.3) & $271(27.0)$ & & $196(23.0)$ & $589(27.0)$ & \\
\hline Grade & & & & 0.883 & & & 0.014 \\
\hline 1 & 107 (3.5) & 73 (3.6) & $34(3.4)$ & & $19(2.2)$ & $88(4.0)$ & \\
\hline$\|$ & $2,123(70.0)$ & $1,416(69.7)$ & 707 (70.6) & & $586(68.9)$ & $1,537(70.4)$ & \\
\hline III & 803 (26.5) & $542(26.7)$ & $261(26.0)$ & & $246(28.9)$ & 557 (25.5) & \\
\hline Pathological MVI & & & & 0.729 & & & $<0.001$ \\
\hline Yes & $314(10.4)$ & $213(10.5)$ & $101(10.1)$ & & $114(13.4)$ & $200(9.2)$ & \\
\hline No & 2,719 (89.6) & $1,818(89.5)$ & 901 (89.9) & & $737(86.6)$ & 1,982 (90.8) & \\
\hline Pathological LVI & & & & 0.399 & & & 0.172 \\
\hline Yes & $19(0.6)$ & $11(0.5)$ & $8(0.8)$ & & $8(0.9)$ & $11(0.5)$ & \\
\hline No & $3,014(99.4)$ & 2,020 (99.5) & 994 (99.2) & & $843(99.1)$ & $2,171(99.5)$ & \\
\hline Positive LN number & & & & 0.965 & & & $<0.001$ \\
\hline 1 & $1,472(48.5)$ & $984(48.4)$ & $488(48.7)$ & & $264(31.0)$ & $1,208(55.4)$ & \\
\hline 2 & $935(30.8)$ & $625(30.8)$ & $310(30.9)$ & & $274(32.2)$ & 661 (30.3) & \\
\hline 3 & $626(20.6)$ & $422(20.8)$ & $204(20.4)$ & & $313(36.8)$ & $313(14.3)$ & \\
\hline Positive LN percentage & & & & 0.851 & & & $<0.001$ \\
\hline$\leq 10 \%$ & 1,905 (62.8) & 1,278 (62.9) & $627(62.6)$ & & $390(45.8)$ & $1,515(69.4)$ & \\
\hline$>10 \%$ & 1,128 (37.2) & $753(37.1)$ & $375(37.4)$ & & $461(54.2)$ & 667 (30.6) & \\
\hline Pathological T stage & & & & 0.509 & & & $<0.001$ \\
\hline $\mathrm{T} 1$ & 1,412 (46.6) & $937(46.1)$ & $475(47.4)$ & & $345(40.5)$ & 1,067 (48.9) & \\
\hline $\mathrm{T} 2$ & $1,621(53.4)$ & 1,094 (53.9) & $527(52.6)$ & & $506(59.5)$ & $1,115(51.1)$ & \\
\hline Molecular subtype & & & & 0.366 & & & $<0.001$ \\
\hline Luminal A & $1,963(64.7)$ & $1,304(64.2)$ & $659(65.8)$ & & $490(57.6)$ & $1,473(67.5)$ & \\
\hline Luminal B & $376(12.4)$ & $244(12.0)$ & $132(13.2)$ & & $115(13.5)$ & $261(12.0)$ & \\
\hline Her2 enriched & $241(7.9)$ & $167(8.2)$ & $74(7.4)$ & & $87(10.2)$ & $154(7.1)$ & \\
\hline Triple negative & $453(14.9)$ & $316(15.6)$ & $137(13.7)$ & & $159(18.7)$ & $294(13.5)$ & \\
\hline ER & & & & 0.009 & & & $<0.001$ \\
\hline Negative & $892(29.4)$ & 628 (30.9) & 264 (26.3) & & 303 (35.6) & $589(27.0)$ & \\
\hline Positive & 2,141 (70.6) & $1,403(69.1)$ & 738 (73.7) & & $548(64.4)$ & 1,593 (73.0) & \\
\hline $\mathrm{PR}$ & & & & 0.167 & & & $<0.001$ \\
\hline Negative & 937 (30.9) & $644(31.7)$ & 293 (29.2) & & 327 (38.4) & $610(28.0)$ & \\
\hline Positive & $2,096(69.1)$ & 1,387 (68.3) & 709 (70.8) & & $524(61.6)$ & $1,572(72.0)$ & \\
\hline Her2 & & & & 0.836 & & & 0.004 \\
\hline Negative & 2,416 (79.7) & 1,620 (79.8) & 796 (79.4) & & 649 (76.3) & 1,767 (81.0) & \\
\hline Positive & 617 (20.3) & $411(20.2)$ & 206 (20.6) & & $202(23.7)$ & 415 (19.0) & \\
\hline $\mathrm{Ki}-67$ & & & & 0.653 & & & $<0.001$ \\
\hline$<30 \%$ & 953 (31.4) & 628 (30.9) & 325 (32.4) & & $253(29.7)$ & 700 (32.1) & \\
\hline$\geq 30 \%$ & 585 (19.3) & 391 (19.3) & $194(19.4)$ & & $206(24.2)$ & $379(17.4)$ & \\
\hline unknown & 1,495 (49.3) & $1,012(49.8)$ & $483(48.2)$ & & $392(46.1)$ & $1,103(50.5)$ & \\
\hline
\end{tabular}

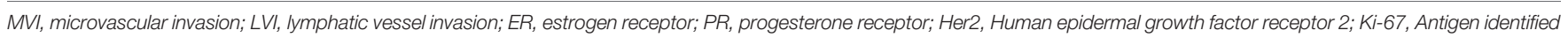
by monoclonal antibody Ki-67; PMRT, Postmastectomy Radiotherapy.

(55.8\%) in supraclavicular lymph nodes, and $36(16.7 \%)$ in internal mammary lymph nodes. According to the total nomogram risk scores of the patients to estimate the probability of 5-year LRFS, the cohort was stratified into three groups ( $\leq 100$, low-risk, $40.0 \%$; $101-$
199, moderate-risk, 42.4\%; $\geq 200$, high-risk, $17.6 \%$ ) representing distinct prognosis. The 5-year outcomes were significantly different among the three groups, with 5-year OS, DFS, and LRFS rates of $95.5,89.8$, and $96.9 \%$ for the low-risk group, 93.8, 84.7, and $93.5 \%$ 
TABLE 2 | Univariate analysis of the association between clinicopathological features and locoregional recurrence-free survival (LRFS) for patients with pT1N1M0 breast cancer in the primary cohort.

\begin{tabular}{|c|c|c|}
\hline \multirow[t]{2}{*}{ Characteristic } & \multicolumn{2}{|c|}{ Primary cohort } \\
\hline & 5-year LRFS (\%) & $P$ value \\
\hline Lateral & & 0.396 \\
\hline Left & 93.0 & \\
\hline Right & 92.9 & \\
\hline Age(y) & & 0.009 \\
\hline$\leq 45$ & 90.6 & \\
\hline$>45$ & 93.8 & \\
\hline Menstrual status & & 0.030 \\
\hline premenopausal & 91.7 & \\
\hline postmenopausal & 94.2 & \\
\hline Coronary disease & & 0.364 \\
\hline No & 93.2 & \\
\hline Yes & 79.7 & \\
\hline Primary tumor site & & 0.004 \\
\hline Lateral & 93.8 & \\
\hline Inner+central & 90.6 & \\
\hline Grade & & 0.380 \\
\hline 1 & 98.3 & \\
\hline$\|$ & 93.0 & \\
\hline III & 91.9 & \\
\hline Pathological MVI & & 0.141 \\
\hline Yes & 93.4 & \\
\hline No & 88.8 & \\
\hline Pathological LVI & & 0.538 \\
\hline Yes & 92.9 & \\
\hline No & 100 & \\
\hline Positive LN number & & 0.001 \\
\hline 1 & 94.4 & \\
\hline 2 & 93.3 & \\
\hline 3 & 86.5 & \\
\hline Positive LN percentage & & 0.002 \\
\hline$\leq 10 \%$ & 94.3 & \\
\hline$>10 \%$ & 89.8 & \\
\hline Pathological T stage & & 0.001 \\
\hline $\mathrm{T} 1$ & 95.8 & \\
\hline $\mathrm{T} 2$ & 90.3 & \\
\hline Molecular subtype & & $<0.001$ \\
\hline Luminal A & 95.6 & \\
\hline Luminal B & 91.0 & \\
\hline Her2 enriched & 87.1 & \\
\hline Triple negative & 84.3 & \\
\hline ER & & $<0.001$ \\
\hline Negative & 86.7 & \\
\hline Positive & 95.5 & \\
\hline PR & & $<0.001$ \\
\hline Negative & 86.4 & \\
\hline Positive & 95.7 & \\
\hline Her2 & & 0.354 \\
\hline Negative & 93.7 & \\
\hline Positive & 89.5 & \\
\hline $\mathrm{Ki}-67$ & & 0.001 \\
\hline$<30 \%$ & 95.8 & \\
\hline$\geq 30 \%$ & 92.6 & \\
\hline Unknown & 91.4 & \\
\hline
\end{tabular}

MVI, microvascular invasion; $L V I$, lymphatic vessel invasion; ER, estrogen receptor; $P R$, progesterone receptor; Her2, Human epidermal growth factor receptor 2; Ki-67, Antigen identified by monoclonal antibody Ki-67; PMRT, Postmastectomy Radiotherapy.

for the moderate-risk group and $85.2 \%(\mathrm{P}<0.001$, Figure 3B $), 73.8 \%$ $(\mathrm{P}<0.001$, Figure $3 \mathrm{C})$, and $85.8 \%(\mathrm{P}<0.001$, Figure 3D) for the highrisk group.
TABLE 3 | Multivariate analysis of the association between clinicopathological features and locoregional recurrence-free survival (LRFS) for patients with pT1N1M0 breast cancer in the primary cohort.

\begin{tabular}{|c|c|c|c|}
\hline \multirow[t]{2}{*}{ Variable } & \multicolumn{3}{|c|}{ LRFS } \\
\hline & HR & $95 \% \mathrm{Cl}$ & P value \\
\hline Age ( $\leq 45 y$ vs. $>45 y)$ & 1.692 & $1.144-2.504$ & 0.008 \\
\hline Primary tumor site (Inner+central vs. Lateral) & 2.013 & $1.365-2.969$ & $<0.001$ \\
\hline Pathological T stage (T2 vs. T1) & 1.942 & $1.294-2.915$ & 0.001 \\
\hline Positive LN number & & & 0.041 \\
\hline 1 & Ref. & Ref. & Ref. \\
\hline 2 & 1.569 & $0.934-2.634$ & 0.089 \\
\hline 3 & 2.310 & $1.205-4.427$ & 0.012 \\
\hline Molecular subtype & & & $<0.001$ \\
\hline Luminal A & Ref. & Ref. & Ref. \\
\hline Luminal B & 1.077 & $0.549-2.114$ & 0.829 \\
\hline Her2 enriched & 2.261 & $1.227-4.167$ & 0.009 \\
\hline Triple negative & 2.675 & $1.693-4.225$ & $<0.001$ \\
\hline
\end{tabular}

HR, Hazard Ratio; Cl, confidence interval; LRFS, locoregional recurrence-free survival.

\section{PMRT Showed Limited Benefit in Low- and Moderate-Risk Group, but Improved Survivals in High-Risk Group}

First, we evaluated the efficacy of PMRT vs. without PMRT. In the unadjusted population, patients treated with PMRT tended to have more risk factors than those without PMRT (Table 1). But they both achieved a good outcome. For all patients, no effective difference was found between with PMRT and without PMRT (5-year OS, 93.3 vs. 92.2\%, $\mathrm{P}=0.256$; 5-year DFS, 82.3 vs. $85.8 \%, \mathrm{P}=0.088$; 5-year LRFS, 94.3 vs. $93.2 \%, \mathrm{P}=0.360)$.

In low-risk group, patients who received PMRT or not both achieved a favorable OS ( 94.4 vs. $95.8 \%, P=0.632$, Figure 4A), DFS ( 86.1 vs. $90.7 \%, \mathrm{P}=0.394$, Figure 4C), and LRFS (96.7 vs. 97.0\%, $\mathrm{P}=0.787$, Figure 4E). Similarly, in moderate-risk group, no differences were found in OS (94.3 vs. 93.7\%, $\mathrm{P}=0.137$, Figure 5A), DFS ( 83.4 vs. $85.2 \%, P=0.332$, Figure 5C), and LRFS (95.3 vs. $92.8 \%, \mathrm{P}=0.308$, Figure 5E) between PMRT or no PMRT patients. In high-risk group, compared with no PMRT, differences were observed in OS ( 86.8 vs. $83.9 \%, \mathrm{P}=0.050$, Figure 6A), DFS (77.2 vs. $70.9 \%, P=0.049$, Figure 6C), and LRFS (90.8 vs. $81.6 \%, \mathrm{P}=0.003$, Figure 6E) of PMRT patients.

After adjustment by PSM, the clinicopathological characteristics of patients in each cohort were balanced between treatment groups (Table 4-6). There were no significant differences in OS, DFS, and LRFS in low-risk group (Figures 4B, D, F) and moderate-risk group (Figures 5B, D, F). In the high-risk group, PMRT still resulted in significantly better OS (89.7 vs. $83.4 \%, \mathrm{P}=0.022$, Figure 6B), DFS (77.1 vs. $71.3 \%$, $\mathrm{P}=0.048$, Figure 6D), and LRFS (91.3 vs. $80.8 \%, \mathrm{P}=0.002$, Figure 6F).

\section{DISCUSSION}

PMRT in T1-2N1 breast cancer is an important clinical study subject that has not been solved due to lack of randomized controlled trails. Our study is a multicenter retrospective study 


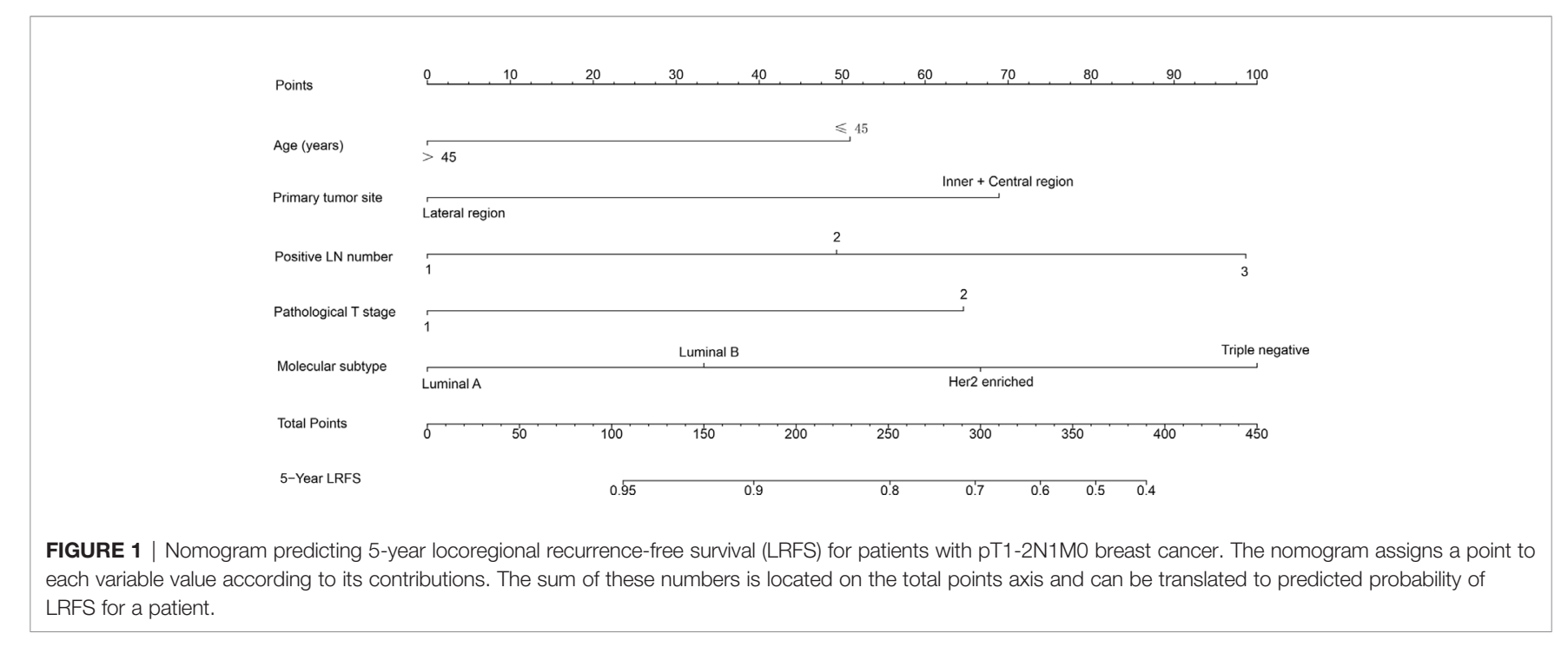

A

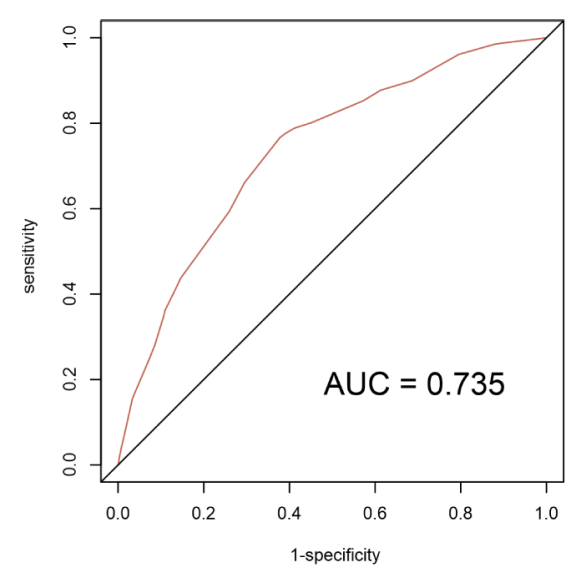

C

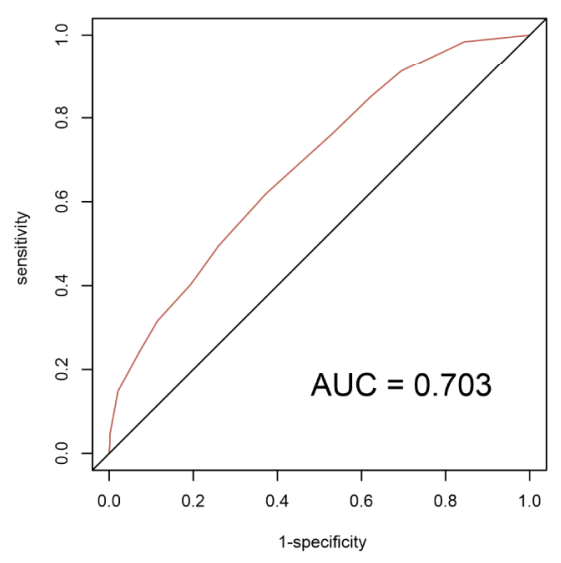

B

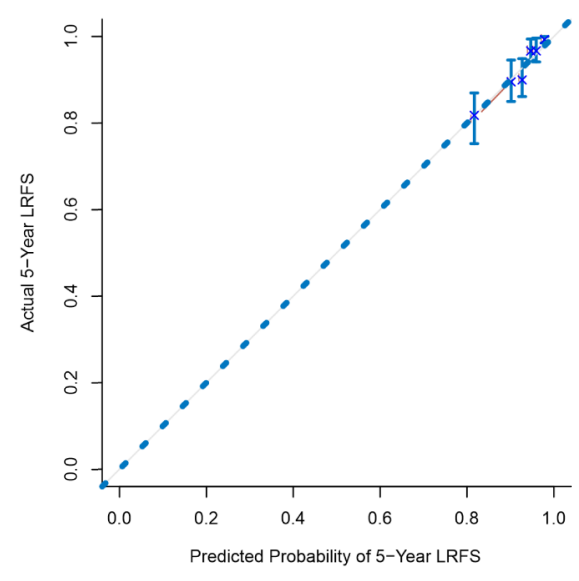

D

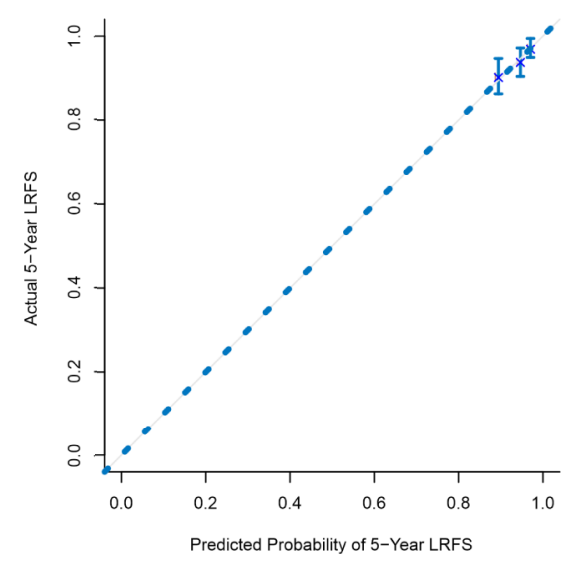

FIGURE 2 | Internal validation of the nomogram to predict LRFS likelihoods in the primary cohort patients. The area under the receiver operating characteristic (ROC) curve (AUC) was 0.735 (A). The calibration curve for the prediction of 5-year LRFS (B). External validation of the nomogram to predict LRFS likelihoods in the validation cohort patients. The area under the receiver operating characteristic (ROC) curve (AUC) was 0.703 (C). The calibration curve for the prediction of 5-year LRFS (D). 
A

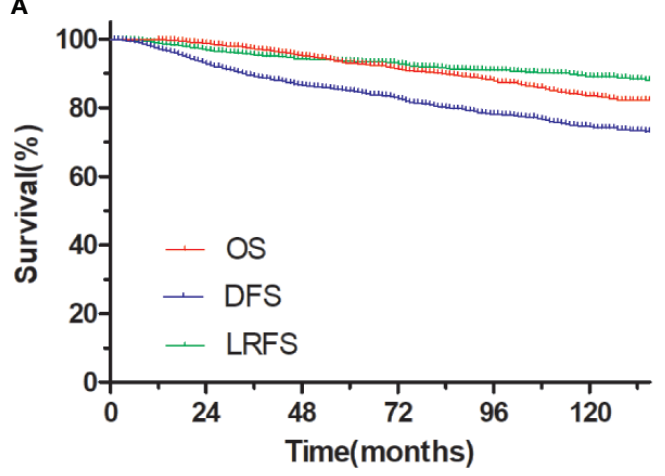

C

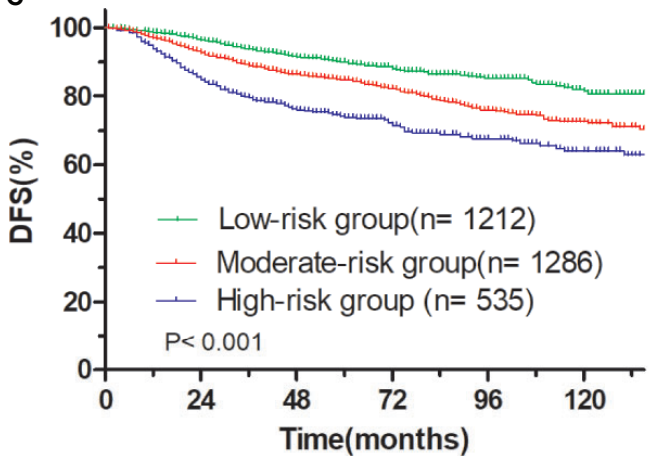

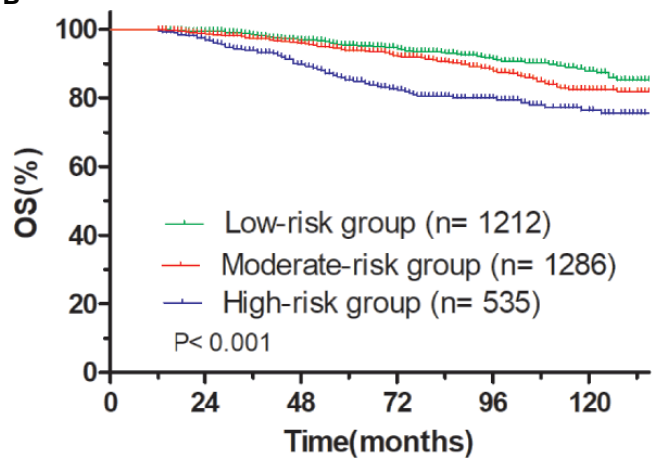

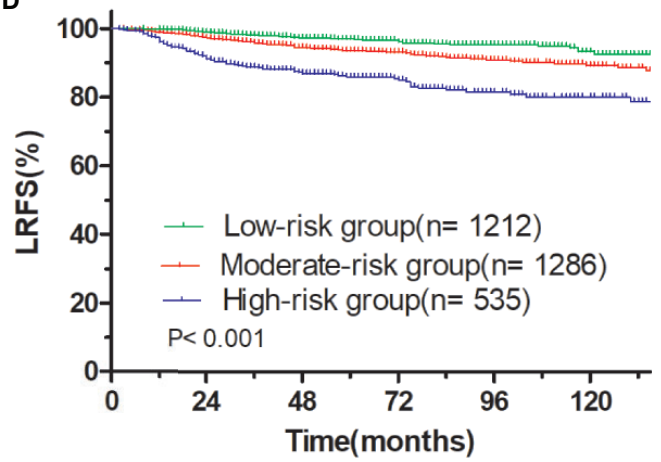

FIGURE 3 | OS and DFS and LRFS for all patients. (A) pT1-2N1MO breast cancer, (B) OS, and (C) DFS, and (D) LRFS for patients with pT1-2N1M0 breast cancer stratified into the low- and moderate- and high-risk groups.

with large sample size, trying to explore the value of PMRT for pT1-2N1M0 breast cancer in the modern era. Our study showed that the overall LRR of pT1-2N1M0 breast cancer after mastectomy is low and the survival rate is high. This is consistent with the international advanced level. In multivariate analysis, age, primary tumor site, $\mathrm{pT}$ stage, number of positive lymph nodes, and molecular subtype were identified as independent risk factors for locoregional recurrence. We developed a nomogram to estimate the probability of 5-year LRFS based on these five variables. Stratified analysis based on the nomogram total risk scores showed that the high-risk group exhibited a high LRR, while the low-risk group had a locoregional recurrence risk $<10 \%$. PMRT significantly improved LRFS of patients in the high-risk group. To our knowledge, this is the first study to develop a pT1-2N1M0 breast cancer-specific nomogram based on a large cohort of patients. The nomogram has been validated as a reliable tool to predict survival in these patients, independent of treatment strategy.

We selected cases treated with systemic therapy since 2000, and data showed that the standards of screening, diagnosis, and treatment for breast cancer continue to improve over time. All patients received standard modified radical mastectomy. More than $80 \%$ patients received paclitaxel chemotherapy. Almost all
ER or PR receptor-positive patients received endocrine therapy, among them, nearly half were treated with AI. In views of the economic factors, $1 / 3$ of HER2-positive patients chose targeted therapy. Then, we divided the entire patients into two groups according to the different institutions. We constructed a prognostic model in four institutions, and observed that the established model still had good predictive efficacy in other two institutions. This led us to further stratify all patients into different risk groups on the nomogram scores.

Emerging evidences have shown that LRR of patients without lymph node metastasis (N0 stage) after mastectomy was less than $10 \%$, and PMRT did not improve LRR. For patients with more than 4 positive lymph nodes, PMRT not only reduced the LRR, but also improved the OS. Meanwhile, the meta-analysis showed that PMRT significantly reduced 5 years LRR (from 16.5 to $3.8 \%$ ) in breast cancer patients with 1-3 positive lymph nodes (N1 stage), and improved the 5,10 , and 20 years survival rates by 5.6 , 9.9, and 7.9\% (14). However, whether all T1-2N1M0 patients need PMRT remains controversial. Firstly, previous results were derived from early studies in which most patients received adriamycin or non-adriamycin chemotherapy without targeted therapy, and randomized trials in the 1980s and early 1990s reported LRRs of 12 to $30 \%$. With the development of systemic 

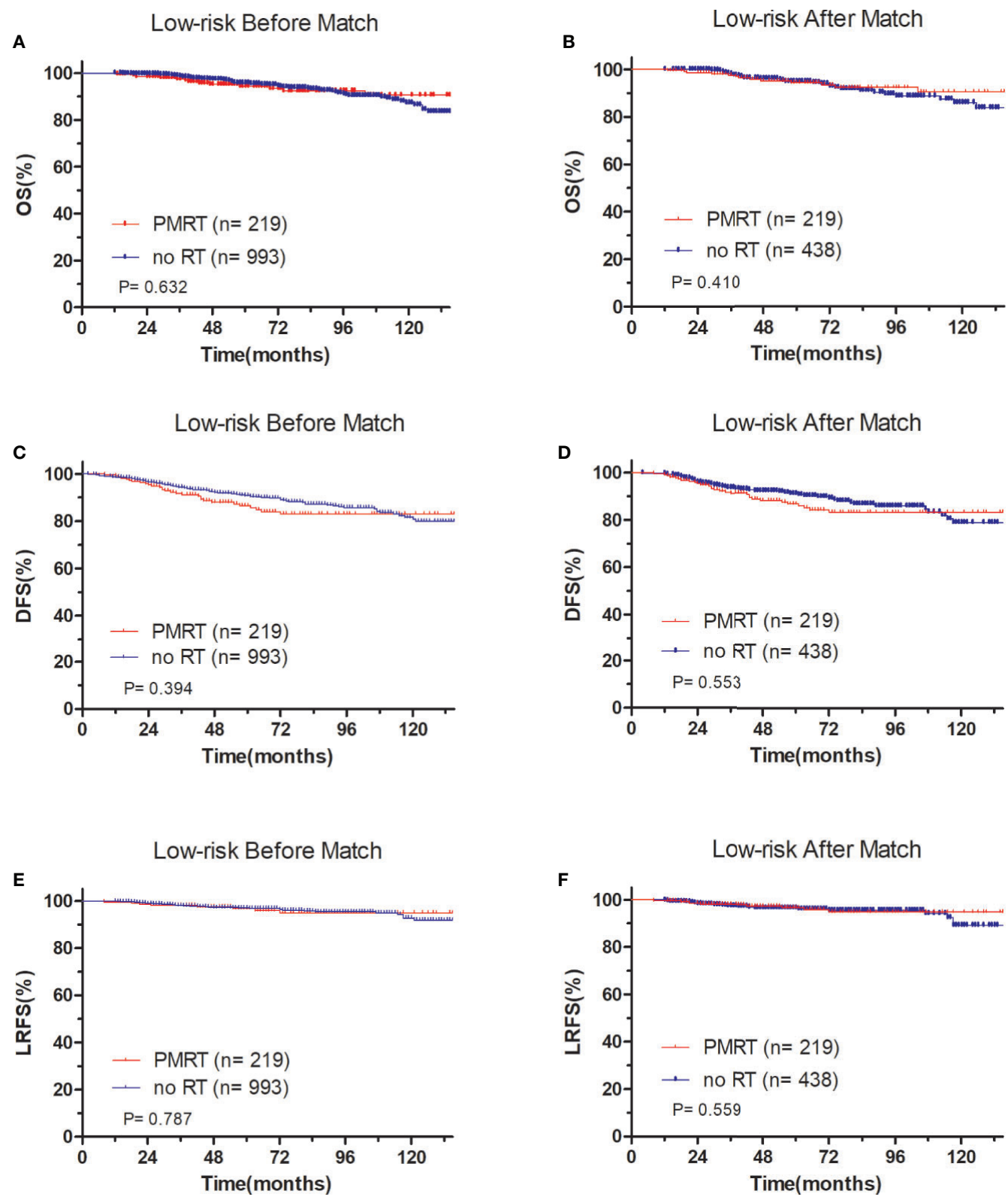

FIGURE 4 | Comparison of OS and DFS and LRFS between with PMRT and without PMRT for low-risk PT1-2N1M0 patients. For patients with PMRT or without PMRT, OS before (A) and after (B) match stratification; DFS before (C) and after (D) match stratification; LRFS before (E) and after (F) match stratification.

therapy in recent years, taxol and targeted therapy further reduced the 10 years LRR to $10-13 \%$ in patients not received PMRT (16-18). Although the LRR is significantly lower than before, it is still possible that PMRT may be benefit for patients with this degree of LRR risk. A previous analysis of MDACC demonstrated that PMRT reduced the 10-year LRR risk from 13 to $3 \%(\mathrm{P}=0.003)(19)$. However, the long-term survival benefit brought by radiotherapy may be reduced. Secondly, there is heterogeneity in pT1-2N1M0 stage breast cancer patients, and the LRR of some low-risk patients is less than $10 \%$. These patients may not need radiotherapy because the long-term survival benefit is very low. Modern changes in management have affected the benefits of PMRT, the reported LRR have further decreased (20-23). According to the latest data of MDACC and MSKCC, the risk of failure of patients treated after 2000 has decreased to about $4 \%$. More recently, a study from MDACC retrospectively analyzed LRR in 1027 T1-2N1 patients during an early era (1978-1997) and a later era (20002007) (24). These eras were divided due to the routine use of standard surgery, taxane chemotherapy, and aromatase inhibitors. Results are similar to our study. In the later era, there are $25 \%$ of the 522 patients with significant higher-risk 


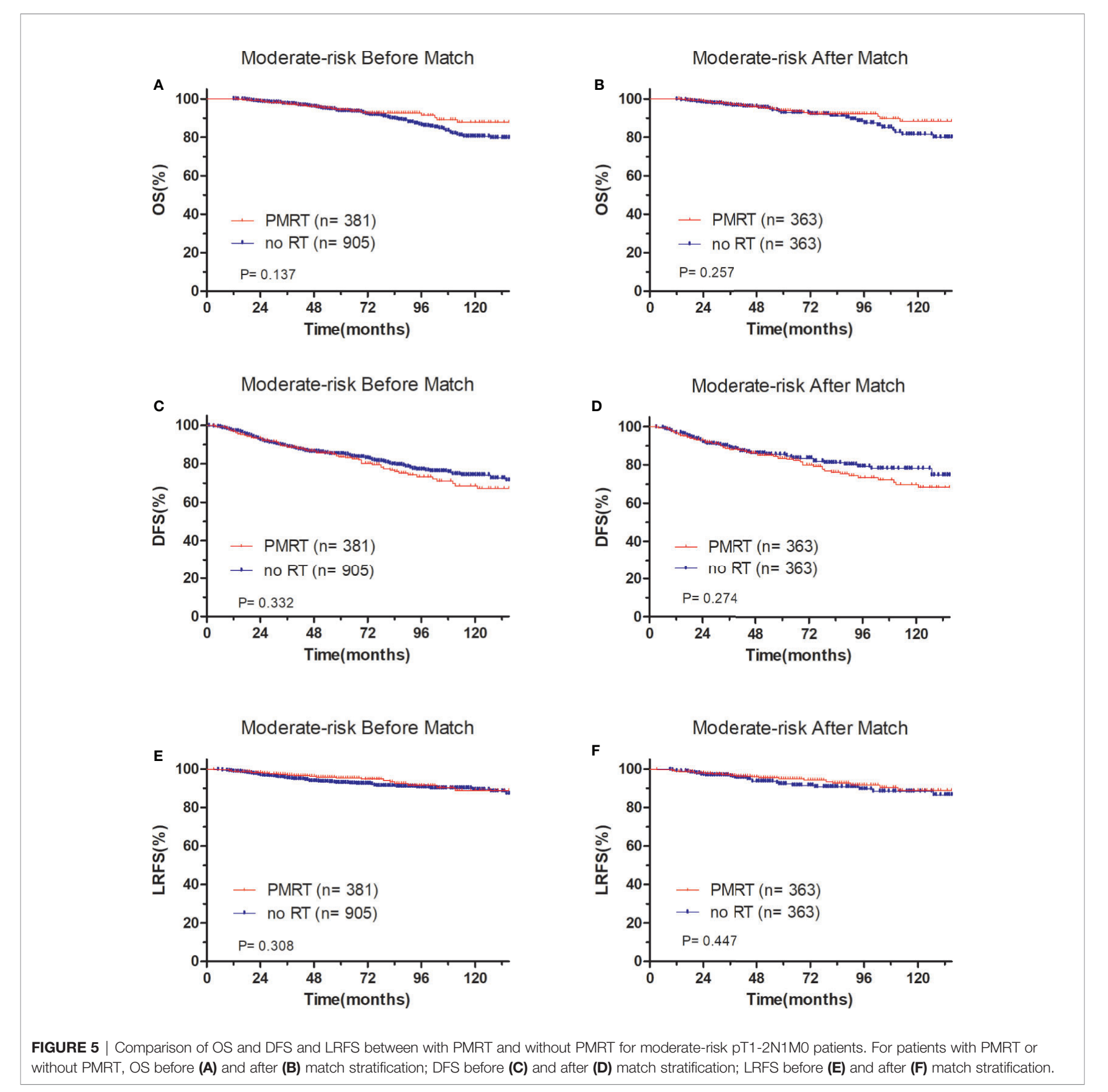

features received PMRT. PMRT did not appear to benefit these patients, with 5 -year LRR of $2.8 \%$ for non-PMRT and $4.2 \%$ for PMRT (HR 1.41, P = 0.48).

With such low LRR in the modern era, PMRT may not benefit all patients with 1-3 positive lymph nodes. Rather than adopting a universal recommendation of PMRT for all N1 patients, many institutional philosophy has been to selectively recommend PMRT for subcategories of patients who have higher-risk features over the past decade. Clinicopathological factors are important factors affecting the LRR of breast cancer. The results of this study showed that we also used these risk factors to select patients for radiotherapy. Current treatment of breast cancer also uses biologic features into clinical decision making (25-29). Previous studies have shown that molecular subtype (MST) can predict recurrence and survival in breast cancer. HER2 enriched and triple negative subtypes has been shown to correlate with the poorest outcomes (30-36). However, there are limited reports on MST association with LRR in the N1 group. A study from MSKCC investigated the association of MST with LRR and PMRT effect among T1-2N1 patients (37). Results showed a trend toward an increase in LRR in the HER2 and basal subtypes (5.4 and 8.8\%, respectively). 


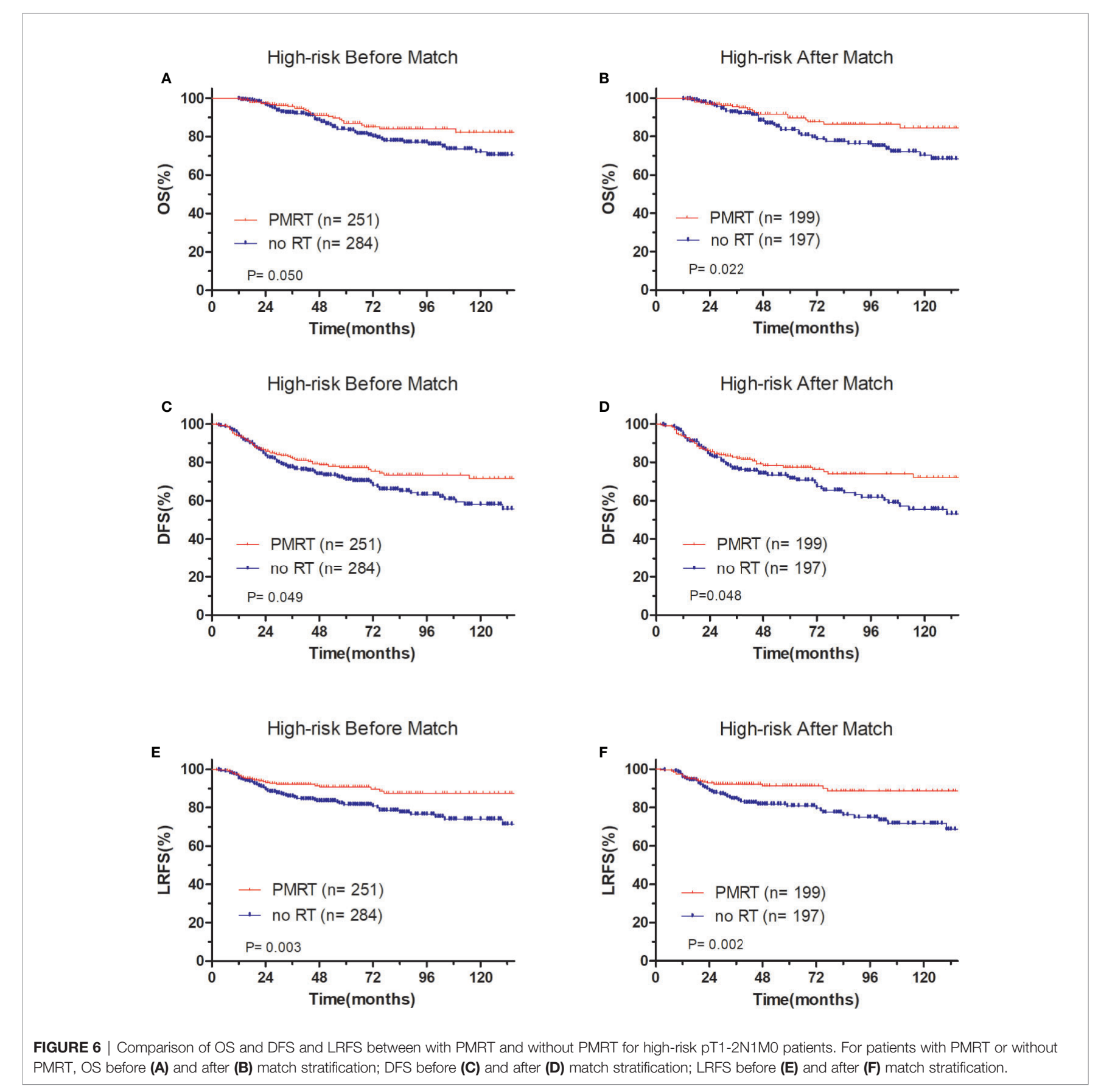

In this study, for the first time, we combined clinicopathological factors with molecular typing to establish a stratified model of prognostic risk, suggesting that the use of appropriate molecular markers may help better screen out patients at high risk of recurrence and avoid overtreatment. Age, site of primary lesion, molecular type, $\mathrm{pT}$ stage and positive lymph nodes number were independent factors affecting LRFS. Low-risk, moderate-risk, and high-risk patients had significantly different outcomes. PMRT reduced the LRR of patients in the high-risk group, and statistically significant improved the DFS rate and OS rate (38).
However, related to the small number of patients and short followup time, whether PMRT can really improve the long-term survival of high-risk patients rely on additional validation with expanded sample size and long-term follow-up, and the results are expected to provide help for phase III clinical research design.

There are some limitations in this retrospective study. Because of the non-random assignment of treatments, highrisk patients were more likely to be selected to receive PMRT. Thus, the survival results may be affected by selection biases. To reduce the influence of this limitation, we used PSM to account 
TABLE 4 | Clinical characteristics of low-risk patients with pT1-2N1M0 breast cancer before and after PSM 1:2 stratification by treatment.

\begin{tabular}{|c|c|c|c|c|c|c|}
\hline \multirow[t]{2}{*}{ Characteristic } & \multicolumn{3}{|c|}{ Before match } & \multicolumn{3}{|c|}{ After match } \\
\hline & PMRT (\%) & No PMRT (\%) & $P$ value & PMRT (\%) & No PMRT (\%) & $P$ value \\
\hline Total & 219 & 993 & - & 219 & 438 & - \\
\hline Age (y) & & & 0.005 & & & 0.562 \\
\hline$\leq 45$ & $50(22.8)$ & $150(15.1)$ & & $50(22.8)$ & $109(24.9)$ & \\
\hline$>45$ & 169 (77.2) & $843(84.9)$ & & 169 (77.2) & $329(75.1)$ & \\
\hline Primary tumor site & & & 0.001 & & & 1.000 \\
\hline lateral & 209 (95.4) & $871(87.7)$ & & 209 (95.4) & $418(95.4)$ & \\
\hline Inner+ central & $10(4.6)$ & $122(12.3)$ & & $10(4.6)$ & $20(4.6)$ & \\
\hline Positive LN number & & & $<0.001$ & & & 0.233 \\
\hline 1 & $133(60.7)$ & $753(75.8)$ & & $133(60.7)$ & $266(60.7)$ & \\
\hline 2 & $53(24.2)$ & $192(19.3)$ & & $53(24.2)$ & $124(28.3)$ & \\
\hline 3 & $33(15.1)$ & $48(4.8)$ & & $33(15.1)$ & $48(11.0)$ & \\
\hline Pathological T stage & & & 0.939 & & & 1.000 \\
\hline $\mathrm{T} 1$ & $171(78.1)$ & $773(77.8)$ & & $171(78.1)$ & $342(78.1)$ & \\
\hline $\mathrm{T} 2$ & $48(21.9)$ & $220(22.2)$ & & $48(21.9)$ & $96(21.9)$ & \\
\hline Molecular subtype & & & 0.942 & & & 0.902 \\
\hline Luminal A & 180 (82.2) & $814(82.0)$ & & 180 (82.2) & $351(80.1)$ & \\
\hline Luminal B & $24(11.0)$ & $110(11.1)$ & & $24(11.0)$ & $57(13.0)$ & \\
\hline Her2 enriched & $5(2.3)$ & $29(2.9)$ & & $5(2.3)$ & $10(2.3)$ & \\
\hline Triple negative & $10(4.6)$ & $40(4.0)$ & & $10(4.6)$ & $20(4.6)$ & \\
\hline
\end{tabular}

PMRT, Postmastectomy Radiotherapy.

TABLE 5 | Clinical characteristics of moderate-risk patients with pT1-2N1M0 breast cancer before and after PSM 1:1 stratification by treatment.

\begin{tabular}{|c|c|c|c|c|c|c|}
\hline \multirow[t]{2}{*}{ Characteristic } & \multicolumn{3}{|c|}{ Before match } & \multicolumn{3}{|c|}{ After match } \\
\hline & PMRT (\%) & No PMRT (\%) & $P$ value & PMRT (\%) & No PMRT (\%) & $P$ value \\
\hline Total & 379 & 840 & - & 363 & 363 & - \\
\hline Age (y) & & & 0.483 & & & 1.000 \\
\hline$\leq 45$ & $140(36.7)$ & $314(34.7)$ & & 127 (35.0) & $127(35.0)$ & \\
\hline$>45$ & 241 (63.3) & $591(65.3)$ & & $236(65.0)$ & $236(65.0)$ & \\
\hline Primary tumor site & & & $<0.001$ & & & 1.000 \\
\hline lateral & 301 (79.0) & $583(64.4)$ & & $286(78.8)$ & $286(78.8)$ & \\
\hline Inner+ central & $80(21.0)$ & $322(35.6)$ & & $77(21.2)$ & $77(21.2)$ & \\
\hline Positive LN percentage & & & $<0.001$ & & & 1.000 \\
\hline 1 & 105 (27.6) & $385(42.5)$ & & 105 (28.9) & 105 (28.9) & \\
\hline 2 & 152 (39.9) & $373(41.2)$ & & $152(41.9)$ & $152(41.9)$ & \\
\hline 3 & $124(32.5)$ & $147(16.2)$ & & $106(29.2)$ & $106(29.2)$ & \\
\hline Pathological T stage & & & 0.037 & & & 1.000 \\
\hline $\mathrm{T} 1$ & $130(34.1)$ & $256(28.3)$ & & $112(30.9)$ & $112(30.9)$ & \\
\hline $\mathrm{T} 2$ & $251(65.9)$ & $649(71.7)$ & & $251(69.1)$ & $251(69.1)$ & \\
\hline Molecular subtype & & & 0.164 & & & 1.000 \\
\hline Luminal A & $225(59.1)$ & $584(64.5)$ & & $212(58.4)$ & $212(58.4)$ & \\
\hline Luminal B & $67(17.6)$ & $122(13.5)$ & & $64(17.6)$ & $64(17.6)$ & \\
\hline Her2 enriched & 47 (12.3) & 96 (10.6) & & $45(12.4)$ & $45(12.4)$ & \\
\hline Triple negative & $42(11.0)$ & $103(11.4)$ & & $42(11.6)$ & $42(11.6)$ & \\
\hline
\end{tabular}

PMRT, Postmastectomy Radiotherapy.

for prognostic factors. The numbers of patients in each treatment group were sufficient to compare survival differences after PSM adjustment.

In conclusion, LRR after mastectomy of pT1-2N1M0 breast cancer is low, but we have developed and externally validated a nomogram that can predict 5-year LRFS with a high degree of accuracy based on a large cohort of patients. Risk-adapted PMRT for high-risk patients is a viable effective strategy based on the total nomogram risk scores. Because MST does predict survival outcomes, it should to be a useful tool to identify patients who would benefit from PMRT in this subgroup. Future prospective studies are required to refine.

\section{DATA AVAILABILITY STATEMENT}

The original contributions presented in the study are included in the article/supplementary material. Further inquiries can be directed to the corresponding author. 
TABLE 6 | Clinical characteristics of high-risk patients with pT1-2N1M0 breast cancer before and after PSM 1:1 stratification by treatment.

\begin{tabular}{|c|c|c|c|c|c|c|}
\hline Characteristic & \multicolumn{3}{|c|}{ Before match } & \multicolumn{3}{|c|}{ After match } \\
\hline Total & 251 & 284 & - & 199 & 197 & - \\
\hline$\leq 45$ & $161(64.1)$ & $167(58.8)$ & & $123(61.8)$ & $121(61.4)$ & \\
\hline$>45$ & $90(35.9)$ & 117 (41.2) & & 76 (38.2) & 76 (38.2) & \\
\hline Primary tumor site & & & 0.041 & & & 0.774 \\
\hline Positive LN percentage & & & $<0.001$ & & & 0.996 \\
\hline 1 & $26(10.4)$ & $70(24.6)$ & & $26(13.1)$ & $26(13.2)$ & \\
\hline 2 & 69 (27.5) & 96 (33.8) & & 64 (32.2) & 64 (32.5) & \\
\hline 3 & $156(62.2)$ & $118(41.5)$ & & $109(54.8)$ & 107 (54.3) & \\
\hline Pathological T stage & & & 0.184 & & & 0.739 \\
\hline $\mathrm{T} 1$ & $44(17.5)$ & $38(13.4)$ & & $26(13.1)$ & $28(14.2)$ & \\
\hline Triple negative & $107(42.6)$ & $151(53.2)$ & & $92(46.2)$ & $93(47.2)$ & \\
\hline
\end{tabular}

PMRT, Postmastectomy Radiotherapy.

\section{ETHICS STATEMENT}

This project was approved by the ethics committee at the Beijing Hospital/National Center of Gerontology and conducted in accordance with the Helsinki Declaration of the World Medical Association (the 5th revision in October 2000).

\section{AUTHOR CONTRIBUTIONS}

ML conceived and designed the experiments. ML, JY, and XW participated in the experiments and drafted the manuscript. ML, JY, XW, BH, QY, PY, ZZ, and QP contributed to the sample collection and interpretation of the data. ML, JY, XW, and WH performed the statistical analysis. BH, QY, PY, ZZ, QP, WH, YX, and $\mathrm{XX}$ revised the manuscript. All authors read and approved

\section{REFERENCES}

1. Wallgren A, Bonetti M, Gelber RD, Goldhirsch A, Castiglione-Gertsch M, Holmberg SB, et al. Risk factors for locoregional recurrence among breast cancer patients: Results from International Breast Cancer Study Group Trials I Through VII. J Clin Oncol (2003) 21:1205-13. doi: 10.1200/JCO.2003.03.130

2. Recht A, Bartelink H, Fourquet A, Fowble B, Haffty BG, Harris JR, et al. Postmastectomy radiotherapy: questions for the twenty-first century. J Clin Oncol (1998) 16:2886-9. doi: 10.1200/JCO.1998.16.8.2886

3. Harris JR, Halpin-Murphy P, McNeese M, Mendenhall NP, Morrow M, Robert NJ. Consensus statement on postmastectomy radiation therapy. Int J Radiat Oncol Biol Phys (1999) 44:989-90. doi: 10.1016/s0360-3016(99)00096-6

4. Recht A, Edge SB, Solin LJ, Robinson DS, Estabrook A, Fine RE, et al. Postmastectomy radiotherapy: Clinical practice guidelines of the American Society of Clinical Oncology. J Clin Oncol (2001) 19:1539-69. doi: 10.1200/ JCO.2001.19.5.1539

5. Olivotto IA, Truong PT, Chua B. Postmastectomy radiation therapy: who needs it? J Clin Oncol (2004) 22:4237-9. doi: 10.1200/JCO.2004.06.974

6. Overgaard M, Hansen PS, Overgaard J, Rose C, Andersson M, Bach F, et al. Postoperative radiotherapy in high-risk premenopausal women with breast the final manuscript. All authors contributed to the article and approved the submitted version.

\section{FUNDING}

This study was supported by a Beijing Hospital Grant (grant number, bj-2018-018) from Beijing Hospital/National Center of Gerontology.

\section{ACKNOWLEDGMENTS}

This study was selected as an ePoster at the American Society for Radiation Oncology (ASTRO) virtual Annual Meeting, October 24-28 (https://doi.org/10.1016/j.ijrobp.2020.07.1022).

cancer who receive adjuvant chemotherapy. Danish Breast Cancer Cooperative Group 82b Trial. N Engl J Med (1997) 337:949-55. doi: 10.1056/NEJM199710023371401

7. Overgaard M, Jensen MB, Overgaard J, Hansen PS, Rose C, Andersson M, et al. Postoperative radiotherapy in high-risk postmenopausal breast cancer patients given adjuvant tamoxifen: Danish Breast Cancer Cooperative Group DBCG 82c randomised trial. Lancet (1999) 353:1641-48. doi: 10.1016/S01406736(98)09201-0

8. EBCTCG (Early Breast Cancer Trialists' Collaborative Group). Favourable and unfavourable effects on long-term survival of radiotherapy for early breast cancer: An overview of the randomised trials. Early Breast Cancer Trialists' Collaborative Group. Lancet (2000) 355:1757-70. doi: 10.1016/ S0140-6736(00)02263-7

9. Ragaz J, Olivotto IA, Spinelli JJ, Phillips N, Jackson SM, Wilson KS, et al. Locoregional radiation therapy in patients with high-risk breast cancer receiving adjuvant chemotherapy: 20-year results of the British Columbia randomized trial. J Natl Cancer Inst (2005) 97:116-26. doi: 10.1093/jnci/ djh297

10. Clarke M, Collins R, Darby S, Davies C, Elphinstone P, Evans V, et al. Effects of radiotherapy and of differences in the extent of surgery for early breast 
cancer on local recurrence and 15-year survival: An overview of the randomised trials. Lancet (2005) 366:2087-106. doi: 10.1016/S0140-6736 (05)67887-7

11. Nielsen HM, Overgaard M, Grau C, Jensen AR, Overgaard J. Loco-regional recurrence after mastectomy in high-risk breast cancer-risk and prognosis: An analysis of patients from the DBCG $82 \mathrm{~B} \& \mathrm{C}$ randomization trials. Radiother Oncol (2006) 79:147-55. doi: 10.1016/j.radonc.2006.04.006

12. Danish Breast Cancer Cooperative Group, Nielsen HM, Overgaard M, Grau C, Jensen AR, Overgaard J. Study of failure pattern among high-risk breast cancer patients with or without postmastectomy radiotherapy in addition to adjuvant systemic therapy: Long-term results from the Danish Breast Cancer Cooperative Group DBCG 82 B and C randomized studies. J Clin Oncol (2006) 24:2268-75. doi: $10.1200 /$ JCO.2005.02.8738

13. Overgaard M, Nielsen HM, Overgaard J. Is the benefit of postmastectomy irradiation limited to patients with four or more positive nodes, as recommended in international consensus reports? A subgroup analysis of the DBCG 82 B\&C randomized trials. Radiother Oncol (2007) 82:247-53. doi: 10.1016/j.radonc.2007.02.001

14. EBCTCG (Early Breast Cancer Trialists' Collaborative Group), McGale P, Taylor C, Correa C, Cutter D, Duane F, et al. Effect of radiotherapy after mastectomy and axillary surgery on 10-year recurrence and 20-year breast cancer mortality: meta-analysis of individual patient data for 8135 women in 22 randomised trials. Lancet (2014) 383:2127-35. doi: 10.1016/S0140-6736 (14)60488-8

15. Arenas M, Selek U, Kaidar-Person O, Perrucci E, Luis AM, Boersma L, et al. The 2018 assisi think tank meeting on breast cancer: International expert panel white paper. Crit Rev Oncol Hematol (2020) 151:102967. doi: 10.1016/ j.critrevonc.2020.102967

16. Recht A, Gray R, Davidson NE, Fowble BL, Solin LJ, Cummings FJ, et al. Locoregional failure 10 years after mastectomy and adjuvant chemotherapy with or without tamoxifen without irradiation: experience of the Eastern Cooperative Oncology Group. J Clin Oncol (1999) 17:1689-700. doi: 10.1200/ JCO.1999.17.6.1689

17. Taghian A, Jeong JH, Mamounas E, Anderson S, Bryant J, Deutsch M, et al. Patterns of locoregional failure in patients with operable breast cancer treated by mastectomy and adjuvant chemotherapy with or without tamoxifen and without radiotherapy: results from five National Surgical Adjuvant Breast and Bowel Project randomized clinical trials. J Clin Oncol (2004) 22:4247-54. doi: 10.1200/JCO.2004.01.042

18. Katz A, Strom EA, Buchholz TA, Thames HD, Smith CD, Jhingran A, et al. Locoregional Recurrence Patterns After Mastectomy and Doxorubicin-Based Chemotherapy: Implications for Postoperative Irradiation. J Clin Oncol (2000) 18:2817-27. doi: 10.1200/JCO.2000.18.15.2817

19. Woodward WA, Strom EA, Tucker SL, Katz A, McNeese MD, Perkins GH, et al. Locoregional recurrence after doxorubicin-based chemotherapy and postmastectomy: Implications for breast cancer patients with early-stage disease and predictors for recurrence after postmastectomy radiation. Int $J$ Radiat Oncol Biol Phys (2003) 57:336-44. doi: 10.1016/s0360-3016(03)00593-5

20. Tendulkar RD, Rehman S, Shukla ME, Reddy CA, Moore H, Budd GT, et al. Impact of postmastectomy radiation on locoregional recurrence in breast cancer patients with 1-3 positive lymph nodes treated with modern systemic therapy. Int J Radiat Oncol Biol Phys (2012) 83:e577-81. doi: 10.1016/ j.ijrobp.2012.01.076

21. Harris EE, Freilich J, Lin HY, Chuong M, Acs G. The impact of the size of nodal metastases on recurrence risk in breast cancer patients with 1-3 positive axillary nodes after mastectomy. Int J Radiat Oncol Biol Phys (2013) 85 (3):609-14. doi: 10.1016/j.ijrobp.2012.05.050

22. Sharma R, Bedrosian I, Lucci A, Hwang RF, Rourke LL, Qiao W, et al. Presentday locoregional control in patients with $\mathrm{t} 1$ or $\mathrm{t} 2$ breast cancer with 0 and 1 to 3 positive lymph nodes after mastectomy without radiotherapy. Ann Surg Oncol (2010) 17:2899-908. doi: 10.1245/s10434-010-1089-x

23. Moo TA, McMillan R, Lee M, Stempel M, Patil S, Ho A, et al. Selection criteria for postmastectomy radiotherapy in t1-t2 tumors with 1 to 3 positive lymph nodes. Ann Surg Oncol (2013) 20:3169-74. doi: 10.1245/s10434-013-3117-0

24. McBride A, Allen P, Woodward W, Kim M, Kuerer HM, Drinka EK, et al. Locoregional Recurrence Risk for Patients With T1,2 Breast Cancer With 1-3 Positive Lymph Nodes Treated With Mastectomy and Systemic Treatment. Int J Radiat Oncol Biol Phys (2014) 89:392-8. doi: 10.1016/j.ijrobp.2014.02.013
25. Lowery AJ, Kell MR, Glynn RW, Kerin MJ, Sweeney KJ. Locoregional recurrence after breast cancer surgery: a systematic review by receptor phenotype. Breast Cancer Res Treat (2012) 133:831-41. doi: 10.1007/ s10549-011-1891-6

26. Truong PT, Olivotto IA, Kader HA, Panades M, Speers CH, Berthelet E. Selecting breast cancer patients with T1-T2 tumors and one to three positive axillary nodes at high postmastectomy locoregional recurrence risk for adjuvant radiotherapy. Int J Radiat Oncol Biol Phys (2005) 61:1337-47. doi: 10.1016/j.ijrobp.2004.08.009

27. Truong PT, Woodward WA, Thames HD, Ragaz J, Olivotto IA, Buchholz TA. The ratio of positive to excised nodes identifies high-risk subsets and reduces inter-institutional differences in locoregional recurrence risk estimates in breast cancer patients with 1-3 positive nodes: an analysis of prospective data from British Columbia and the M. D. Anderson Cancer Center. Int J Radiat Oncol Biol Phys (2007) 68:59-65. doi: 10.1016/j.jirobp.2006.12.017

28. Karlsson P, Cole BF, Chua BH, Price KN, Lindtner J, Collins JP, et al. Patterns and risk factors for locoregional failures after mastectomy for breast cancer: an International Breast Cancer Study Group report. Ann Oncol (2012) 23:28528. doi: 10.1093/annonc/mds118

29. Tong CWS, Wu M, Cho WCS. To KKW.Recent Advances in the Treatment of Breast Cancer. Front Oncol (2018) 8:227. doi: 10.3389/fonc.2018.00227

30. Kyndi M, Sørensen FB, Knudsen H, Overgaard M, Nielsen HM, Overgaard J, et al. Estrogen receptor, progesterone receptor, HER-2, and response to postmastectomy radiotherapy in high risk breast cancer: the Danish Breast Cancer Cooperative Group. J Clin Oncol (2008) 26:1419-26. doi: 10.1200/JCO.2007.14.5565

31. Nguyen PL, Taghian AG, Katz MS, Niemierko A, Abi Raad RF, Boon WL, et al. Breast cancer subtype approximated by estrogen receptor, progesterone receptor, and HER-2 is associated with local and distant recurrence after breast-conserving therapy. J Clin Oncol (2008) 26:2373-8. doi: 10.1200/JCO.2007.14.4287

32. Millar EK, Graham PH, O’Toole SA, McNeil CM, Browne L, Morey AL, et al. Prediction of local recurrence, distant metastases, and death after breastconserving therapy in early-stage invasive breast cancer using a fivebiomarker panel. J Clin Oncol (2009) 27:4701-8. doi: 10.1200/JCO.2008.21.7075

33. Voduc KD, Cheang MC, Tyldesley S, Gelmon K, Nielsen TO, Kennecke H. Breast cancer subtypes and the risk of local and regional relapse. J Clin Oncol (2010) 28:1684-91. doi: 10.1200/JCO.2009.24.9284

34. Dominici LS, Mittendorf EA, Wang X, Liu J, Kuerer HM, Hunt KK, et al. Implications of constructed biologic subtype and its relationship to locoregional recurrence following mastectomy. Breast Cancer Res (2012) 14: R82. doi: $10.1186 / b c r 3197$

35. Wang Y, Cao S, Chen Y. Molecular Treatment of Different Breast Cancers. Anticancer Agents Med Chem (2015) 15:701-20. doi: 10.2174/1871520615666 150129211901

36. Waks AG, Winer EP. Breast Cancer Treatment: A Review. JAMA (2019) 321:288-300. doi: 10.1001/jama.2018.19323

37. Moo TA, McMillan R, Lee M, Stempel M, Ho A, Patil S, et al. Impact of Molecular Subtype on Locoregional Recurrence in Mastectomy Patients with T1-T2 Breast Cancer and 1-3 Positive Lymph Nodes. Ann Surg Oncol (2014) 21:1569-74. doi: 10.1245/s10434-014-3488-X

38. Li M, Yue J, Wan X, Hua B, Yang Q, Yang P, et al. Risk-Adapted Postmastectomy Radiotherapy Strategies Based on Prognostic Nomogram for pT1-2N1M0 Breast Cancer: A Multicenter Study. Int J Radiat Oncol Biol Phys Supplement (2020) 180:e14. doi: 10.1016/j.ijrobp.2020.07.1022

Conflict of Interest: Authors YX and XX were employed by company GeneplusBeijing Institute.

The remaining authors declare that the research was conducted in the absence of any commercial or financial relationships that could be construed as a potential conflict of interest.

Copyright $\odot 2020$ Li, Yue, Wan, Hua, Yang, Yang, Zhang, Pei, Han, Xu and Xia. This is an open-access article distributed under the terms of the Creative Commons Attribution License (CC BY). The use, distribution or reproduction in other forums is permitted, provided the original author(s) and the copyright owner(s) are credited and that the original publication in this journal is cited, in accordance with accepted academic practice. No use, distribution or reproduction is permitted which does not comply with these terms. 